\section{Unilateral Pulmonary Oedema after Drainage of Spontaneous Pneumothorax}

\author{
GURSHARAN SINGH SAINI
}

British Medical fournal, 1974, 1, 615

\section{Case Report}

A 21-year-old man was admitted to hospital with a seven-day history of dyspnoea of sudden onset. Chest $\boldsymbol{x}$-ray examination on admission showed a complete left pneumothorax, which was treated by closed underwater drainage. Air drained freely through the catheter as soon as it was inserted, and a film taken 10 minutes later showed almost complete re-expansion of the left lung (fig. 1). Shortly after insertion of the intercostal catheter the patient developed a cough and his condition began to deteriorate. Three hours later his blood pressure had fallen from $130 / 90$ to $98 / 60 \mathrm{~mm} \mathrm{Hg}$ and he developed a tachycardia $(120 / \mathrm{min})$. By that time he was producing blood-stained frothy sputum and crepitations were heard over the left lung. A portable chest $x$-ray film (fig. 2) showed pulmonary oedema confined to the left lung. Immediately the intercostal catheter was clamped and he was given continuous oxygen by nasal catheter and an injection of diazepam (Valium) $5 \mathrm{mg}$ intramuscularly. Thereafter his condition steadily improved and eight hours later his blood pressure and pulse were normal and he said he felt perfectly well. Radiologically appreciable clearing of the pulmonary oedema was seen. $X$-ray examination 60 hours later showed complete clearing of the pulmonary oedema and he was discharged on the fourth day.

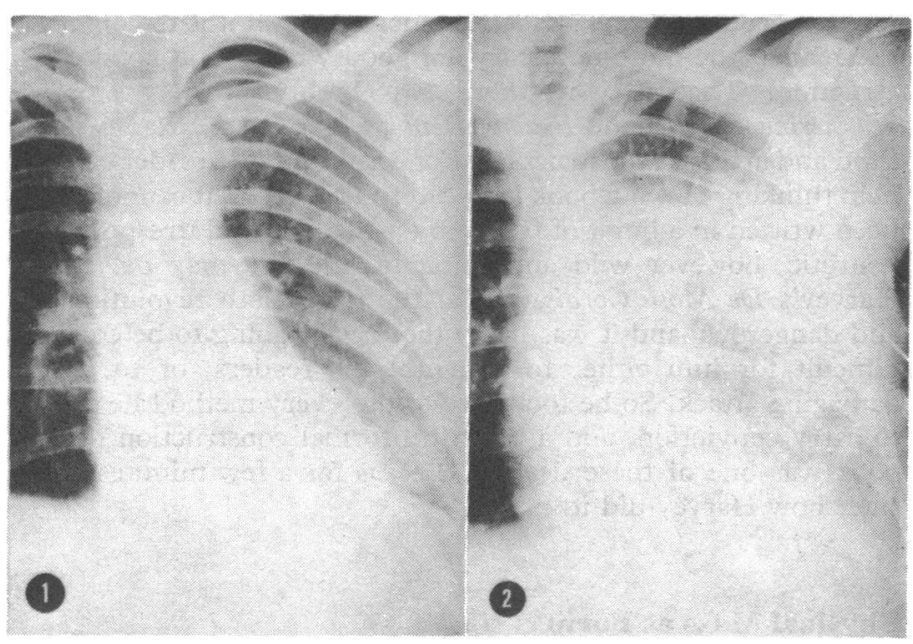

FIG. 1-Complete re-expansion of left lung after insertion of intercostal catheter. FIG. 2-Portable $x$-ray film showing pulmonary oedema confined to left lung.

Seaham Hall Hospital, Seaham, Co. Durham

GURSHARAN SINGH SAINI, M.B., B.S., Senior House Officer, Scartho Road Hospital, Grimsby, Lincs.

\section{Comment}

The treatment of a spontaneous pneumothorax is usually uncomplicated. This case is of interest because of severe unilateral pulmonary oedema which developed after treatment with closed underwater-seal drainage. This rare complication is not mentioned in standard textbooks. We were able to trace only seven cases (Ziskind et al., 1965; Humphreys and Berne, 1970; Trapnell and Thurston, 1970; Childress et al., 1971; Grant, 1971). Four of the seven developed this complication only after application of negative intrapleural pressure by suction pump.

The features of this case were: a large volume of air had been present in the pleural vacity for a week before insertion of the intercostal catheter, pulmonary oedema developed without application of negative pressure by suction pump, the early onset of coughing during or soon after aspiration-which could have been early evidence of this rare complication-and disappearance of the oedema rapidly and progressively with no apparent sequelae.

The mechanism by which the oedema appears is not fully understood. It seems likely that loss of surfactant in the alveoli may be a contributory factor. When a lung is rendered airless from whatever cause the quantity of surfactant present is gradually reduced in the affected part and re-expansion may then be more difficult to achieve (Avery and Chernick, 1963; Finley et al., 1964). If the lung is forcibly "sucked" apart by the creation of a strong negative pressure around it leakage of fluid from the lung capillaries into the connective tissue and alveolar spaces seems a likely sequel (Trapnell and Thurston, 1970).

Another possible explanation is that rapid re-expansion of the collapsed lung causes a sudden increase in the negative intrapleural pressure (Humphreys and Berne, 1970), and experimental work has shown that expansion of a lung in a negativepressure chamber results in a rapid increase in pulmonary capillary pressure and blood flow (Barach et al., 1938). This rapid return of pulmonary blood flow at a high pressure may result in fluid transudation across the capillary and alevolar membranes as well as the accumulation of interstitial oedema.

Unilateral pulmonary oedema usually occurs where part or the whole of a lung has been compressed and airless for a long period if aspiration of the air or fluid responsible is undertaken too quickly. This seems to have been the case in this patient. It seems wise, therefore, to aspirate slowly and not to connect the underwater-seal tube to the suction pump for a day or two. If cough starts early during the procedure it is advisable to clamp the tube to prevent rapid re-expansion of collapsed lung. This complication is more likely to occur when the lung has been compressed for some time by a large volume of air.

I should like to thank Dr. R. Ramsay for his help and for permission to report this case.

Address for reprints: G.S.S., New Rochelle Hospital Medical Center, New Rochelle, N.Y. 10802, U.S.A.

\section{References}

Avery, M. E., and Chernick, V. J. (1963). Pediatrics, 63, 762.

Barach, A., Martin, J., and Eck, Mass M. (1938). Annals of Internal Medicine, $12,764$.

Childress, Max E., Moy, Grant, and Mottram, Martha (1971). American Review of Respiratory Diseases, $104,119$.

Finley, T. N., Tooley, W. H., Swenson, E. W., Gardner, R. E., and Clements, J.' (1964). American Review of Respiratory Diseases, 89, 372.

Grant, M. J. A. (1971). New Zealand Medical Fournal, 74, 250.

Humphreys, R. L., and Berne, A. S. (1970). Radiology, 96, 509.

Trapnell, D. H., and Thurston, J. G. B. (1970). Lancet, 1, 1367.

Ziskind, M. M., Weil, H., and George, R. (1965). American Review of Respiratory Diseases, $92,632$. 